\title{
WHAT KIND OF NATIONAL PARKS DO WE WANT?
}

From time to time we have encouraging evidence of the community o: interests shared by people interested in natural history and those specifically interested in game resources. This was shown, for example, in a meeting helc in Calgary on March 28 to discusis national parks policy. At this meeting a number of organizations with different objectives were represented, including the Canadian Wildlife Federation. The C.W.F., as represented by its executive director, Mr. R. C. Passmore, was able to find a basis for common agreement with organizations like the Nature Conservancy. From the discussions, a policy for parks was spelled out, from which Mr. Passmore cites the following main points:

1. That national parks should, essentially, be national wilderness parks in which enjoyment of only those types of recreation completely appropriate to wilderness would be encouraged. Developments (such as campsites and other service facilities) designed to facilitate enjoyment of the wilderness should be on the periphery of the wilderness but within the boundaries of the national wilderness park.

2. Commercial facilities for providing holiday recreation at any season of the year should be provided adjacent to but outside the boundaries of every national wilderneiss park on lands controlled by either federal or provincial government but developed under a strict zoning program. Where such areas are now contained within the borders of national parks, park boundaries should be redrawn so as to exclude them from within the boundaries of national wilderness parks.

3. The federal and provincial governments should be urged to co-operate fully in establishing several new national wilderness parks while suitable areas are still available.

4. Adoption of a new parks Act which would establish the boundaries of wilderness areas in legislation and which would provide for such other types of national lands as national sea shores and national wild rivers.

5. Adoption of a national wildlife Act which would make provision for national nature preserves and national wildlife lands to be administered by the Canadian Wildlife Service.

6. Establishment of a Commission or Crown Corporation to acquire and manage national wilderness parks, national seashores, national wild rivers and national historic sites.

It seems to me that this is just the kind of thing that the Saskatchewan Natural History Society has been saying, and the kind of thought that lies behind our persistent effort to promote the establishment of the new grasslands park. There is, however, still a "selling job" to be done, for the opposition of certain groups of Saskatchewan people to such a park is real and recognized, and undoubtedly is partly responsible for the provincial government's reluctance to make lands available for it. So we welcome the opportunity to join with these other organizations which are supporting an enlightened national parks policy.

I think that we should not underestimate the effect that public opinion has on government policy. Even private individuals writing to members and cabinet ministers can have influence, if enough people do this. I have just received an answer to a letter I wrote to the Minister of Indian Affairs and Northern Development about our grassiland park proposial and about the establishment of a national park in the East Arm area of Great Slave Lake, in which Mr. Chrétien makes this very point. "It is necessary," he says, "to have such a body of public opinion in order that general and long term benefits may be assesised in comparison with more specific interests and benefits." 